\title{
PERCEPÇÃO AMBIENTAL E ATIVIDADE TURÍSTICA NO PARQUE ESTADUAL DO GUARTELÁ - TIBAGI - PR
}

\author{
Environmental perception and tourism in State Park of Guartelá - \\ Tibagi-PR-Brazil
}

\author{
Evandro da Silva PINHEIRO'
}

\begin{abstract}
RESUMO
Este estudo analisa as interações e influências recíprocas entre o homem e o meio ambiente, geradas através da atividade turística. O Turismo tem se apropriado dos espaços, urbanos e rurais, nem sempre de forma planejada. Ao contrário, o imediatismo financeiro tem prevalecido na maioria dos casos, resultando em reações negativas ou entendimentos inapropriados quanto ao uso de áreas naturais para lazer, e em conseqüentes impactos negativos. O estudo leva em conta a percepção dos visitantes e sua compreensão sobre o espaço. Percepção entendida como um reflexo imediato da interação dos sentidos (visão, audição, olfato, tato) e dos valores pessoais (caráter, personalidade, cultura etc.). Compreensão, sobre sua conduta, sobre seu papel e reflexos na conservação do ambiente visitado. O objeto de análise foi o Parque Estadual do Guartelá (PEG), localizado no Município de Tibagi, Estado do Paraná. Apoiando-se em bases teóricometodológicas do campo de estudo da percepção geográfica, visa-se identificar/analisar/compreender e demonstrar como a percepção dos visitantes na área do PEG revela os processos subjetivos que perpassam a interação homem-ambiente. Os resultados são tratados como instrumentos nos planejamentos voltados às melhores práticas do turismo em áreas naturais, propondo-se estratégias e ações, voltadas a promover o envolvimento desses visitantes através de corretos procedimentos na recepção e orientação e adequadas estruturações.
\end{abstract}

\section{Palavras-chave:}

Percepção ambiental; interação; conduta; ambiente; turismo; áreas naturais.

\section{ABSTRACT}

This study analyzes mutual influence and relationship among environmental and man, respected to the tourist activity. Tourism has been appropriated the spaces, nor ever well planed, particularly those one with natural heritage. In other side, financial interest has been prevailed over another, resulting negatives impacts by using natural areas for leisure. Treating those questions tourist perception and space comprehension might be considered. Perception, think over immediate reflection of feelings interactions (vision, hearing, sense of smell, touch) and personals values (character, personality, cultural, etc). Comprehension, about your behavior, your function and reflection on environmental conservation. This study was done in State Park of Guartelá, Tibagi town, Paraná State. The methodological theories of geographical perception supported how to identify/ analyze/ comprehend and demonstrate as tourist perception in PEG show theirs subjective process from environmental/ man relationships. This dissertation gives a support to the planes how to practice tourism in natural areas, proposing actions that wrap up (involve) the tourist by the correct behavior during receptions and well done structures.

\section{Key-words:}

Environmental perception; relationship; conduct; behavior; tourism; environmental; natural area.

\footnotetext{
${ }^{1}$ Engenheiro Agrônomo pela Esal/USP-1973; Bacharel em Turismo pela UFPR-1998; Especialista em Ecoturismo pelo IBPEX-2000; Mestrado em Geografia pela UFPR-2004; atualmente no IAP-Instituto Ambiental do Paraná.
} 


\section{INTRODUÇÃO}

Este texto foi elaborado a partir de pesquisas no campo da percepção, formando uma base teóricometodológica em revisões bibliográficas e entrevistas com visitantes do Parque Estadual do Guartelá (PEG), no município de Tibagi-PR. Os estudos fundamentaram a dissertação de mestrado, na qual questionamos "qual a percepção e compreensão dos visitantes no Parque Estadual do Guartelá, Tibagi-PR, sobre a atividade turística/de lazer e o ambiente que lhes são ofertados como produto turístico²?".

Respondemos a esse problema, identificando a percepção do visitante sobre as relações com o ambiente ao praticar atividades turísticas permitidas no PEG.

Especificamente buscamos identificar o grau de satisfação do visitante sobre as estruturas, serviços e a qualidade dos atrativos, e saber qual era sua compreensão sobre os impactos positivos e negativos gerados pela visitação.

O estudo analisou as interações e influências recíprocas entre o homem e o meio ambiente geradas pela atividade turística. $O$ tratamento dessas questões levou em conta a percepção dos visitantes e seu entendimento do espaço. Percepção entendida como um reflexo imediato da interação dos sentidos (visão, audição, olfato, tato) e dos valores pessoais (caráter, personalidade, cultura, etc.), revelando os processos subjetivos que perpassam a interação homem-ambiente.

Planejamentos inadequados geram apropriações dos espaços naturais de forma desordenada, muitas vezes sem qualquer ação educativa e orientadora ao visitante sobre o ambiente natural e as possíveis formas de interação.

Os resultados comprovaram que o envolvimento dos visitantes, através de informações sobre o PEG e questões ambientais, o levaria à tomada de consciência sobre sua conduta naquela Unidade de Conservação $(\mathrm{UC})^{3}$, participando na manutenção da qualidade do produto turístico. Os resultados deram suporte às propostas de estratégias e ações na promoção da Educação Ambiental aos visitantes, à administração da referida UC, bem como serviram de subsídio para o uso de outras áreas naturais.

\section{O PARQUE ESTADUAL DO GUARTELÁ (PEG) NO CONTEXTO MUNICIPAL E REGIONAL}

O PEG está situado na região dos Campos Gerais, centro-leste do Estado do Paraná, microrregião geográfica de Telêmaco Borba, município de Tibagi, bairro Guartelá de Cima à margem esquerda do canyon do rio lapó, tendo como centro as coordenadas $24^{\circ} 34^{\prime}$ sul do Equador e $50^{\circ} 14^{\prime}$ oeste de Greenwich.

O acesso é pela PR-340, a $18 \mathrm{~km}$ da cidade de Tibagi e a $42 \mathrm{~km}$ de Castro. Limita-se ao Norte e Leste com o rio lapó; à NW, ao SW e a Oeste com propriedades particulares sendo divisores as vertentes e sangas que alimentam o córrego Pedregulho.

Foi instituído em 27/03/92, pelo Decreto 1229, com área de 4.389 ha, sendo recriado pelo Decreto 2329, em 24/09/96, com área total de 798,97 ha, e é administrado pelo Instituto Ambiental do Paraná (IAP), autarquia da Secretaria de Estado do Meio Ambiente e Recursos Hídricos (SEMA).

O artigo $2^{\circ}$ do Decreto de Criação do Parque cita como objetivo geral da Unidade de Conservação "assegurar a preservação dos ecossistemas típicos, locais de excepcional beleza cênica como "canyons" e cachoeiras, além de significativo patrimônio espeleológico, arqueológico e pré-histórico, em especial pinturas rupestres".

Inserido na Área de Proteção Ambiental da Escarpa Devoniana, $2^{\circ}$ planalto paranaense, apresenta relevo ondulado a escarpado, feição moldada por um canyon com aproximadamente $32 \mathrm{~km}$ de extensão, nos municípios de Castro e Tibagi, talhado pelo leito do rio lapó, um dos principais afluentes do rio Tibagi.

O relevo recortado resultou numa paisagem singular de belezas cênicas únicas com alto grau de atratividade turística. Foram identificadas pinturas rupestres, artefatos líticos e cerâmicas de grupos dos paleoíndios, compondo um grande sítio arqueológico que se estende além da Unidade de Conservação.

A maior parte da vegetação no PEG enquadra-se nas formações de estepes, além de outros tipos vegetacionais, tais como floresta ombrófila mista e uma pequena porção de cerrado, constituindo distintos hábitats para uma fauna muito diversificada em aves, répteis e representantes da mastofauna, como felinos e canídeos.

\footnotetext{
${ }^{2}$ Produto turístico - "Conjunto de bens e serviços turísticos, atrações, acessos e facilidades colocados no mercado, à disposição de visitantes e turistas, em conjunto ou individualmente, visando atender suas necessidades, solicitações ou desejos" (PARANÁ, 2000).

${ }^{3}$ Unidade de conservação - "Espaço territorial e seus recursos ambientais, incluindo as águas jurisdicionais, com características naturais relevantes, legalmente instituído pelo Poder Público, com objetivos de conservação e limites definidos, sob regime especial de administração, ao qual se aplicam garantias adequadas de proteção" (BRASIL, 2000).
} 


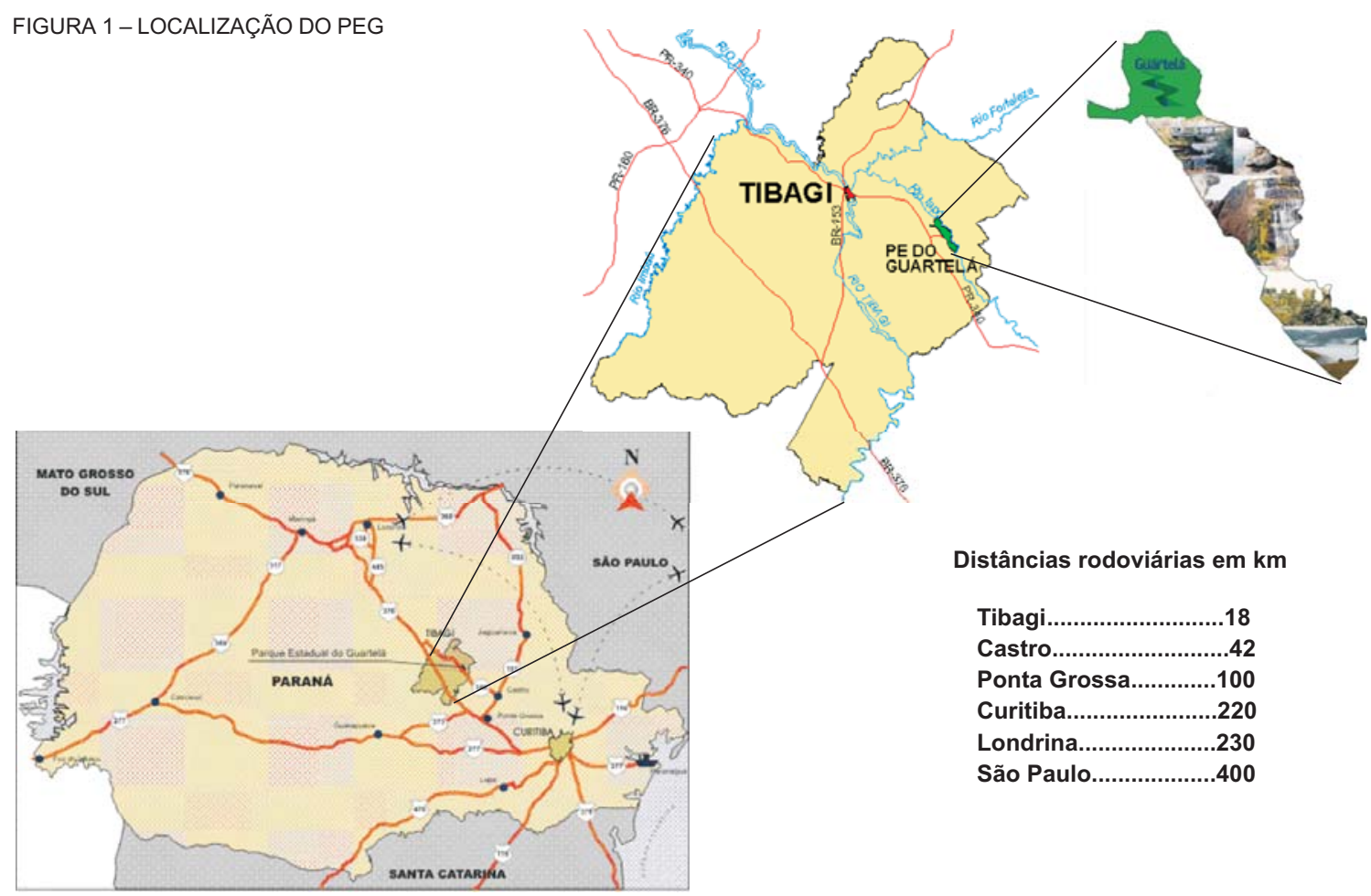

ILUSTRAÇÃO PINHEIRO FONTE: STCP, 2002

O ambiente nos Campos Gerais passou por diferentes fases expansio-nistas do homem e vem sofrendo os reflexos das interferências nos recursos naturais. Houve crescimentos em todos os setores da economia, mas com altos custos sociais e à administração pública. O custo ambiental vem refletindo na piora da qualidade do ar, da água e do solo, prejudicando a flora, a fauna e o homem.

Constata-se, pois, a necessidade de planejamento e programas macrorregionais e neles, os planos e projetos individuais, visando diminuir ou evitar os impactos negativos por ações antrópicas e contemplar as contribuições positivas. Neste contexto, o setor turístico demanda as mesmas preocupações para o manejo dos seus componentes, de forma sustentável, para atingir o desenvolvimento.

O PEG, considerado como bom destino para o Turismo em Áreas Naturais ${ }^{4}$, modalidade Ecoturismo, tem incrementado a economia municipal e regional.

O fluxo turístico é composto por pessoas com diferentes valores culturais, algumas sensíveis às questões ambientais, a maioria de pessoas curiosas, mas inconscientes quanto a forma, intensidade e que atividades sejam compatíveis aos ambientes naturais.
A categoria de manejo "Parque", de proteção integral, permite o uso indireto do patrimônio natural, sendo que em BRASIL (2000, art. 11) versa-se que ela

tem como objetivo básico a preservação de ecossistemas naturais de grande relevância ecológica e beleza cênica, possibilitando a realização de pesquisas científicas e o desenvolvimento de atividades de educação e interpretação ambiental, de recreação em contato com a natureza e de turismo ecológico.

A Figura 2 ilustra os atrativos e estruturas disponíveis ao uso público.

\section{ATIVIDADE TURÍSTICA INTERAGINDO DE FORMA INTEGRADA COM O AMBIENTE CONSTRUÍDO SO- CIALMENTE E A PAISAGEM PERCEBIDA EXPERIEN- CIALMENTE}

O homem sempre expressou sua percepção sobre as relações e interações com o meio em que viveu, buscando fontes de inspiração nos mais diversos fenômenos, fossem climáticos ou decorrentes de suas ações sobre o ambiente. Por meio dos registros ao longo dos

${ }^{4}$ Turismo em Áreas Naturais - "Segmento do turismo que utiliza o patrimônio natural e cultural, de forma sustentável, com intercâmbio sob diferentes formas entre o homem e a natureza, para promover a conservação dos recursos locais (físicos e humanos), otimizando os custos e ganhos ambientais, culturais, econômicos e sociais, orientado por planejamentos participativos" (PARANÁ, 2000). 


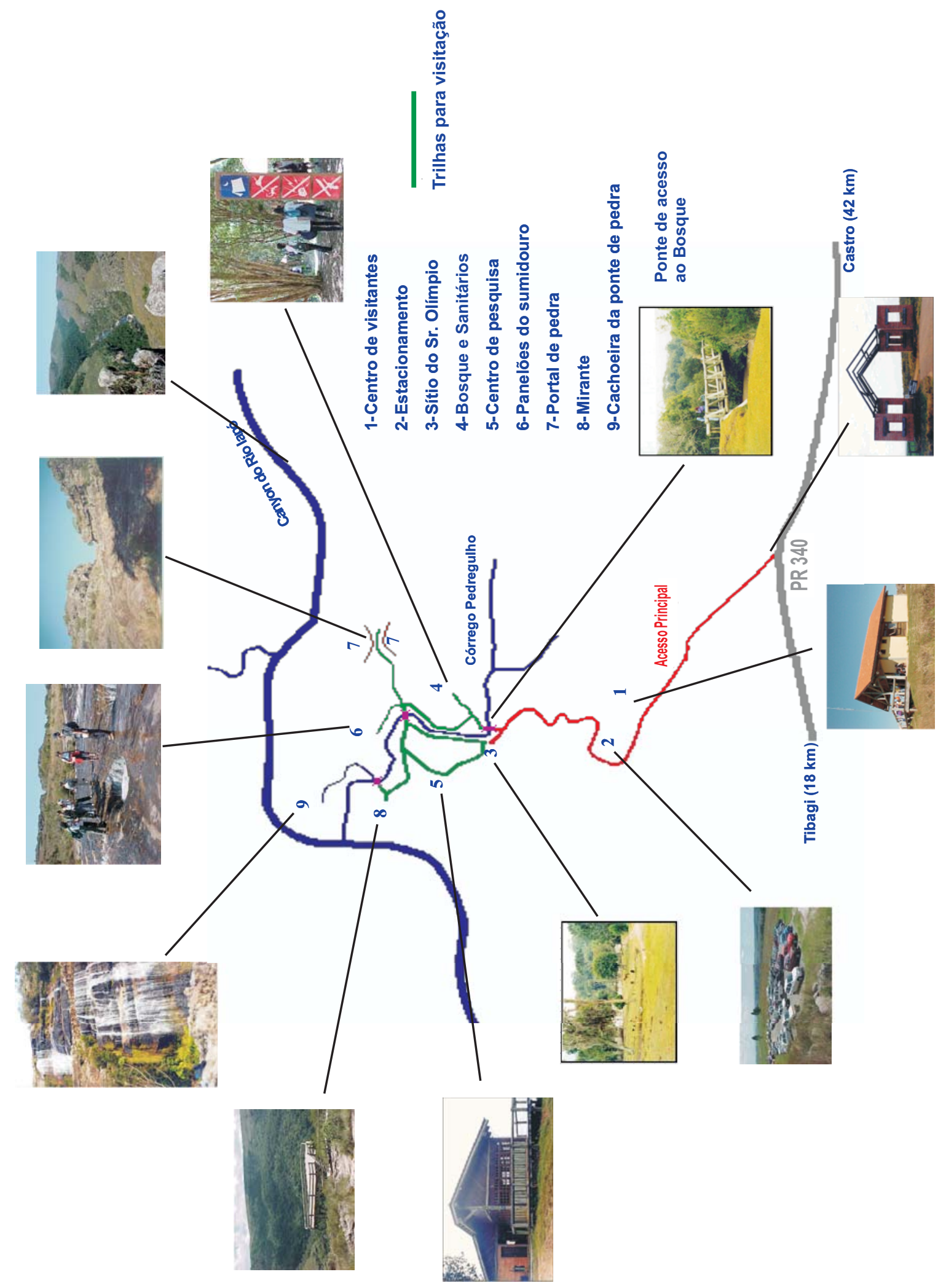

FIGURA 2 - CROQUI DE LOCALIZAÇÃO DOS ATRATIVOS E ESTRUTURAS FOTOS: EVANDRO PINHEIRO; MARIA ANGELA DALCOMUNE; STCP, 2002 
tempos, contando sua história, mostrava a relação com a natureza, apropriando-se dos recursos naturais para atender a suas necessidades.

Em qualquer situação, num tempo e local, ocupamos um lugar ou nos inserimos no espaço, interagindo com o ambiente sob diversas formas, na intensidade e tempo.

Na Figura 3, procuramos representar essa interação do homem com o ambiente em que ele estiver praticando suas atividades, sejam econômicas, de estudo, pessoais ou de lazer, e os reflexos sobre ambos. Nos apropriamos do conceito de ambiente de Silveira (2002) por propiciar um entendimento mais amplo.

Silveira (2002) conceitua como meio-ambiente um sistema aberto em que se inserem outros ambientes onde o homem esteja exercendo suas atividades. A intensidade, a forma, o tipo de atividade e o perfil do praticante são condicionantes que determinarão o nível de influências e o reflexo na qualidade ambiental.

Portanto, seja pela ótica da produção, quando uma área está disponível como reguladora de estoque de recursos bióticos e minerais, ou pelo ambiente construído, ou ainda por algo intangível como a paisagem, a qualidade ambiental passa a ser valorada tal qual a matéria-prima para transformação, com valor de uso e troca.

A paisagem é dimensionada, valorada e agregada como componente formador de produtos de lazer ${ }^{5} \mathrm{e}$ turismo. Ela revela características dos ambientes percebidos ou vivenciados pelo homem (visitante e local), como citado por Heimstra (1978, p. 4-7).

Tuan (1982, p.148-149) comenta que na história da relação homem-ambiente, para os grupos nômades caçadores-coletores, o território não era uma área circunscrita, apenas para atender às necessidades básicas, mas suas fronteiras eram imaginárias ou experienciadas, ao contrário dos proprietários atuais que tem um forte senso de espaço construído, delimitado, ou seja, de seu território.

$\mathrm{Na}$ amplitude do território, à medida que se vivencia e se estabelecem valores ao espaço, o significado se funde com o de lugar, como conceituado por Tuan (1983, p. 6): "espaço é mais abstrato do que lugar". O autor escreve com síntese e clareza ímpares: "espaço e lugar são termos familiares que indicam experiências comuns [...] o lugar é segurança e o espaço é liberdade: estamos ligados ao primeiro e desejamos o outro". (TUAN, 1983, p. 3).

FIGURA 3 - QUALIDADE AMBIENTAL X ATIVIDADES HUMANAS INTERAÇÕES E INFLUÊNCIAS RECÍPROCAS

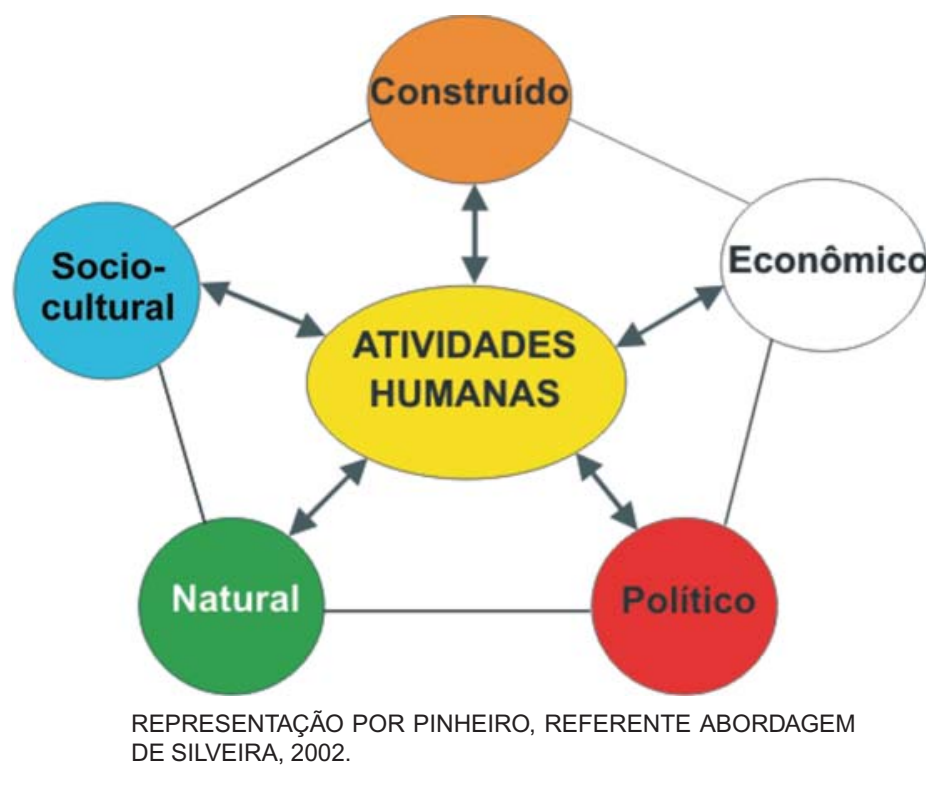

${ }^{5}$ Ao lermos Dumazedier (1979, p. 87-128), no Capítulo "A querela das definições", observamos que ele preconiza várias definições: - mesmo o trabalho profissional pode vir a ser um lazer; - o lazer em referência ao não-trabalho, assim como Karl Marx o define em várias citações em relação ao trabalho profissional; - a exclusão das obrigações doméstico-familiares; - e ao que o autor demonstra sua tendência, ao longo da obra, ao "destinar o vocábulo lazer [...] ao tempo outorgado ao indivíduo pela sociedade quando este se desempenhou, segundo as normas sociais do momento, de suas obrigações profissionais, familiares, sócio-espirtuais e sócio-políticas". 
A dimensão conceituada ao "lugar" nos remete à abordagem psicológica da introspecção, de forte conotação emocional e humanística. Nessa linha, Tuan (1983, p. 151) cita que "o espaço transforma-se em lugar à medida que adquire definição e significado", resultante de aspectos nas relações homem-ambiente: natureza e intensidade da experiência; qualidade da ligação emocional aos aspectos físicos; as funções dos conceitos e símbolos na criação da identidade do lugar. Todas elas são formas do homem perceber o meio com o qual interage pelo corpo, pela ação e pelos sentidos que ele constrói ao se apropriar do espaço.

Nas décadas de 1960 e 1970 "a Geografia passou a utilizar a experiência vivida como instrumento de investigação [...] objetivando interpretar o sentimento e o entendimento dos seres humanos a respeito do espaço e do lugar" (MELLO, 1990, p. 91-92).

$\mathrm{O}$ ambiente e o homem, inseridos na paisagem, revelam informações que são vistas e sentidas na relação de uso e interação. De um lado estão as características do ambiente, com formas e sentidos; de outro o indivíduo que vê, sente ou percebe a sua volta sob prismas/valores culturais, vivos, carregados de significados.

Dessa forma Santos (1997, p. 62) pode ter sido mais abrangente ao citar que "[...] a dimensão da paisagem é a dimensão da percepção, que chega aos sentidos". É a dimensão do que é visualizado, numa amplitude maior que o espaço. Une-se assim o perceptor ao objeto focalizado, imaginado, sentido, vindo à tona valores, juízos, julgando a estética sob enfoques pessoais e familiares.

A familiaridade de um lugar é comentada por VeIho (1978, p. 39-44) como forma de apreensão da realidade, "fazendo com que as opiniões, vivências e percepções de pessoas sem formação acadêmica ou sem pretensões científicas possam dar valiosas contribuições para o conhecimento da vida social, de uma época, de um grupo". São aspectos importantes ao turismo e à preservação da autenticidade da localidade.

Denota-se que não se deve ter um enfoque determinista, mas considerar a subjetividade do observador. Bettanini (1982, p. 72-76) afirma que o comportamento sobre uma paisagem não é supostamente objetivo, mas a subjetividade de sua percepção. Ao questionar "qual é a imagem que os homens ou grupos sociais possuem dos lugares", busca associar as relações homem-ambiente como algo reflexivo.

A resposta estará atrelada a três componentes que devem ser planejados harmoniosamente na manutenção da integridade do ambiente e propiciar maior satisfação ao observador: a qualidade do atrativo; estruturas físicas mais adequadas ao ambiente e ao uso que se propõe; serviços prestados profissionalmente em coerência sociocultural.

Estruturas e serviços devem compor formas e processos facilitadores à interpretação ambiental, como instrumento de comunicação com o morador, o visitante e o guia. Trabalha-se não só a estética e o belo, mas toda a semiótica e os signos, como afirma Moesch (2002, p. 43) que "o olhar é construído por meio de signos, e o turismo abrange uma coleção de signos".

O Turismo, em crescente expansão, vem se apropriando dos espaços, exigindo estruturas e alterações nos ambientes e interferindo nas paisagens, com resultados já conhecidos nas tradicionais formas de produção de bens: maior produção de resíduos; degradação do ambiente. Sem planejamento, contribuirá para destruição do hábitat e perda da integridade ambiental, tornando a atividade insustentável. A sustentabilidade no turismo passa obrigatoriamente pelo planejamento integrado e participativo, este como instrumento de gestão territorial, indicando melhor uso e interação com o meio.

Yazigi (1996, p. 135), nos mostra a estreita relação do espaço com a formação do produto turístico, afirmando que "o espaço pode ser considerado como a matéria-prima do turismo", e complementa, "[...] as condições naturais, o patrimônio cultural e histórico, o potencial técnico e o ambiente econômico são igualmente critérios geográficos que intervêm, seja sozinho, seja em combinação, nos diferentes tipos de turismo"

Boullón (1985, p. 93-161), estudou a paisagem como formadora do produto turístico, seu uso indireto e intangível nos espaços naturais, ainda os aspectos da formação e qualidade do que é oferecido ao consumidor. Ele entende que a captação e apreensão da realidade se dão de forma fragmentada, mas não isolada, denominando de visão em série, uma recordação das imagens percebidas. Enfoca que o impacto visual da paisagem sobre o visitante está relacionado ao tipo de atividade praticada no ambiente. Comenta sobre pessoas participativas, as que compreendem seu papel em áreas naturais e aquelas que "no sabe cómo comportarse ni donde ir si no cuenta con ayuda externa".

Qualquer que seja o tipo de atividade praticada é importante entender qual a percepção e compreensão que o visitante tem sobre sua participação em momentos de lazer no ambiente que lhe é ofertado como produto turístico.

Os estudos da percepção e do comportamento contribuem, mediante representações e simbologias,

${ }^{6}$ LOZATO-GIOTART, J.P. Geographie du turisme. Paris: Masson, 1993. p. 35. 
para a compreensão das relações homem-ambiente, e de como o homem interage com o meio na construção de seu território, sua cultura e sua história.

Enfocando as relações entre produtor-consumidor, Gade (1980, p. 47) conceituou: "Percepção se refere aos processos pelos quais o indivíduo recebe estímulos através dos seus vários sentidos e os interpreta".

Para Tuan (1980, p. 4) a percepção "é tanto a resposta dos sentidos aos estímulos externos, como a atividade proposital na qual certos fenômenos são claramente registrados enquanto outros são bloqueados". Afirmou ainda que o homem é um animal visual, ou seja, dependente mais da visão que dos demais sentidos para sentir conscientemente o mundo que o cerca. O lado inconsciente ou subliminado, o pensamento (realidade objetiva) e o sentimento (estado subjetivo), assim como os valores culturais também contribuem para a percepção de onde estamos.

Complementando Tuan (1983, p. 11) nota-se que ver, pensar e sentir são processos intimamente relacionados, os quais permitem ao perceptor "vivenciar o meio". A visão é um processo seletivo e criativo em que os estímulos do ambiente são organizados em estruturas que fornecem sinais significativos, que se complementam com tato, olfato, audição e paladar na percepção do lugar e espaço e sua realidade.

Ou seja, "a percepção é um processo mental de interação do indivíduo com o meio ambiente que se dá através de mecanismos perceptivos propriamente ditos e, principalmente, cognitivo" (DEL RIO, 1996, p.3).

Cada pessoa recebe a expressão da realidade (ou o ambiente) e a interpreta pela percepção, seja o ato de observar (estudar, olhar crítico) ou contemplar simplesmente de forma gratuita, sem compromisso, na proximidade com o ócio, como observado por Bruhns (1999, p. 128). Seu nível de satisfação vem a ser o atendimento às expectativas subliminadas, despertadas ou motivadas.

A Figura 4, criada por Pinheiro (2000, p. 12) e revisada em Pinheiro (2004, p. 41), ilustra a relação do perceptor com o meio que o envolve, que com ele interage. O perceptor vivencia o ambiente atrelado aos seus valores individuais e subjetivos, resultando em diferentes graus de satisfação ou insatisfação co-relacionados ao estágio de integridade do ambiente com o qual interage. Dessa interação é que entendemos levar à aplicação dos processos para sensibilização e conscientização, posterior ao processo racional da satisfação/insatisfação.

Nessa ilustração ousamos representar o próprio conceito de topofilia, criado por Yi-Fu-Tuan, em que define como "o elo afetivo entre a pessoa e o lugar ou ambiente físico". Afirma em seguida que embora seja "difuso como conceito, é vívido e concreto como experiência pessoal" (TUAN, 1980, p. 5).

Nos referenciamos em Oliveira (1996, p. 203) para concluirmos que, em qualquer situação, os componentes da paisagem oferecem informações que são pro-
ILUSTRAÇÃO PINHEIRO, 2000 E REVISADO NESTE TEXTO

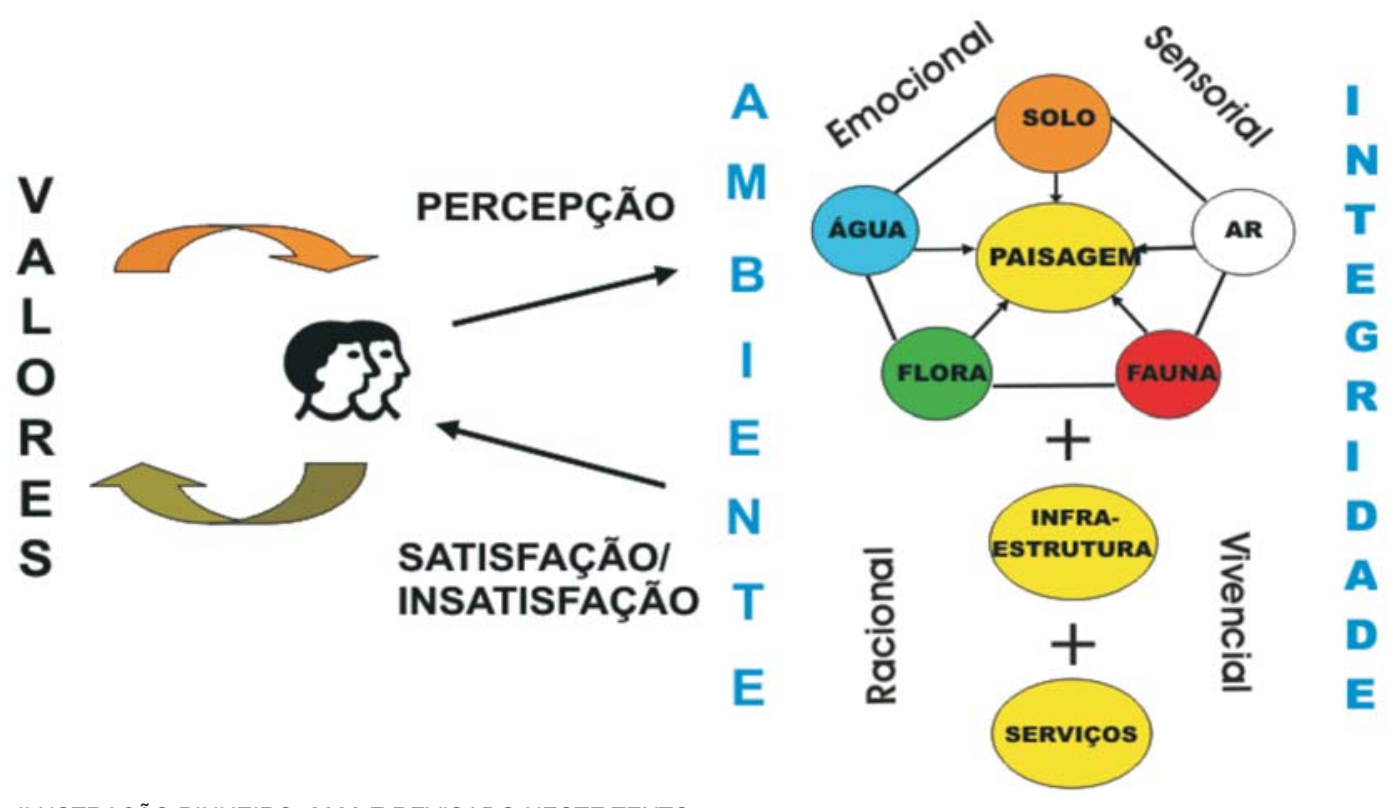


cessadas de forma sensorial, visual, ou seja, presencial; ou de forma racional e simbólica, pela mente, utilizando o atributo da inteligência.

Deparamo-nos com valores individuais, socioculturais, do visitante e do morador, que percebem o mesmo ambiente de formas diferentes e, relacionando em cada situação, à sua familiaridade, a sonhos e fantasias e ao sentido de beleza e estética.

Tuan (1980, p. 74-75), ao analisar como o visitante e o morador local percebem o meio-ambiente, afirma que a avaliação da paisagem é essencialmente estética, sendo que a beleza ou feiúra tende "a desaparecer no subconsciente à medida que ele aprende a viver nesse mundo". Quis o autor se referir à facilidade de adaptabilidade das pessoas às condições de vida a que são expostas, passando a não mais perceberem, com o tempo, fatos e imagens que antes Ihes pareciam diferentes, seja como visitantes ou novos moradores. Ou seja, fatos e objetos podem ser percebidos sob diferentes formas, sensações individualizadas no tempo e segundo a instância em que ocorre a interação.

Nessa perspectiva é que observamos a importância de se compreender o processo da percepção do ambiente, da paisagem onde o homem, empreendendo constantes intervenções em seu espaço, agrega valores ao objeto, que será "consumido" pelo próprio homem por meio das suas atividades humanas, entre elas o turismo.

\section{PERCEPÇÃO E CONDUTA DO VISITANTE NO AMBI- ENTE COM O QUAL ELE INTERAGE}

Nos estudos da percepção são indissociáveis o sujeito e objeto, o perceptor e o que é experienciado, sentido e construído, num processo contínuo, consciente ou subliminado, que vai do racional e simbólico ao sensorial e emocional, levando a experiências individuais e únicas. Diferentes valores e comportamentos resultarão da compreensão, pelo perceptor, sobre sua relação com o ambiente.

Nessa linha, pesquisamos, no PEG, a percepção e compreensão dos visitantes ao exercer atividades de lazer. Procuramos identificar as motivações na busca por áreas naturais, seu grau de satisfação sobre o produto turístico oferecido e sua compreensão sobre os impactos negativos e/ou positivos gerados pela visitação.

Entrevistamos 30 visitantes de forma aleatória simples em duas etapas, uma no Mirante e outra no Centro de Visitantes. Enfatizamos a análise qualitativa com poucas abordagens quantitativas. Assim, as amostragens não seguiram o modelo matemático para cálculo do número de entrevistas.
Os dados foram registrados e tratados em tabelas, e as respostas às perguntas abertas foram analisadas em conjunto, relevadas as observações que pudessem dar conta das hipóteses, dos objetivos e do problema. Registramos e analisamos comportamentos de alguns grupos ou pessoas isoladas.

Resultados mostraram contradições de alguns entrevistados entre motivações e compreensão sobre seu papel no ambiente natural em momentos de lazer. Os valores pessoais levam cada visitante a perceber o mesmo ambiente sob diferentes "olhares".

\section{PERFIL DOS ENTREVISTADOS}

Os dados mostraram $70 \%$ dos visitantes do sexo masculino, sendo $30 \%$ na faixa etária de 15 a 25 anos e $50 \%$ entre 26 a 45 anos, procedente de Curitiba (61\%), $83 \%$ com escolaridade de $3^{\circ}$ grau e $70 \%$ permaneceu de 2 a 4 horas no PEG.

A amostragem define um usuário mais maduro, profissional de boa escolaridade, estabelecido em Curitiba, permanecendo por um tempo suficiente para a visitação mais usual. Informaram-se sobre o PEG na mídia mas a maior parte foi com amigos.

\section{MOTIVAÇÕES E ATIVIDADES}

A maioria dos visitantes se deslocou para realizar um "passeio" diferente com a família, sem conotações às questões ambientais. A segunda maior citação, "interesse pela paisagem", correlaciona-se à fotografia e à apreciação da paisagem, atividades permitidas no PEG. As citações "passeio", "caminhar" foram displicentes e descompromissadas com o real objetivo de uma UC.

Constatamos pessoas que gostariam de praticar atividades mais radicais como rapel e rafting, não permitidas naquela UC. Gostariam de "mais áreas para banho", "abertura de novas e mais extensas trilhas" e "acesso à base da cachoeira".

Alguns visitantes desconheciam que não se podia mais acampar e utilizar as churrasqueiras, gerando reclamações pela falta de informação.

\section{SATISFAÇÃO/INSATISFAÇÃO}

Esta análise quantitativa contribuiu para se conhecer o visitante e compreender seus posicionamentos. O grau de satisfação ficou acima de $70 \%$ como "bom" nos quatro itens "atrativos, infra-estrutura, serviços e atividades". Apenas os serviços tiveram um grau de insatisfação de $27 \%$, sendo $14 \%$ ruim e $13 \%$ regular. Solicitamos opinião sobre monitores, as informações/ orientações recebidas e o material impresso. 


\section{DA INFORMAÇÃO À COMPREENSÃO}

Tanto Gade (1980) quanto Heimstra (1978) concluem que a informação prestada ao visitante, do simbólico ao verbal, são mecanismos cognitivos que contribuem à percepção e compreensão racionais de seu ambiente. Consideraram ter recebido orientações, $77 \%$ dos entrevistados, embora $67 \%$ responderam que faltou clareza de conteúdo ou forma naquele serviço. Material impresso é importante no processo de comunicação ao visitante, para que ele possa conhecer melhor a área visitada. Constatamos que o único material disponível não atendia às necessidades do visitante.

Maior exigência quanto a informações e orientações aos visitantes ficou evidenciada através das citações sobre "folhetaria", atendimento/informação e sinalização, que totalizaram 13 citações como sugestões para melhorar o PEG.

\section{IMPACTOS E RESPONSABILIDADES}

A visitação às áreas naturais gera impactos? Observamos $53 \%$ dos entrevistados afirmarem que a visitação em áreas naturais gera impactos negativos, e quando lhes perguntamos, de forma aberta, quais seriam esses impactos, $46 \%$ responderam, com sete citações para a palavra "degradação" e as demais foram para "depredação, poluição, lixo, barulho, trilhas depredadas". Numa entrevista, o visitante respondeu que a visitação em áreas naturais não geraria impactos negativos, no entanto, ao relatar sua percepção sobre uma foto com muitas pessoas no PEG, referiu-se como poluição visual e que não deveria ser permitida tal aglomeração. O fato de $47 \%$ dos entrevistados responderem que a visitação não geraria impactos negativos pode estar relacionado à desinformação ou à ausência de valores que os levem à percepção das interações e influências recíprocas entre as atividades e o ambiente. Sobre impactos positivos, apesar de $93 \%$ responderem positivamente, não houve qualquer citação de quais poderiam ser os impactos positivos.

Que assuntos você relacionaria com as visitas em áreas naturais? Verificamos que os assuntos listados, sobre aspectos negativos, como: lixo/poluição; perigo; aumento dos preços na cidade; desconforto e pessoas estranhas receberam $20 \%$ das citações. As citações sobre assuntos positivos receberam $75 \%$, tendo como temas principais as viagens, lazer, apreciar a paisagem, história-cultura e preservação ambiental, respondendo de certa forma à questão anterior.

Quem seriam os responsáveis pela conservação ambiental do PEG? Os entrevistados se posicionaram como co-responsáveis pela conservação ambiental do PEG, com $24 \%$ das citações, sendo mais citado com
$41 \%$ o Governo Estadual. Toda a sociedade deveria ser responsável na gestão de áreas protegidas públicas, mas $10 \%$ das citações foram para esta resposta.

O que sugere para melhorar o PEG? Os visitantes mostraram sua insatisfação com os serviços informativos/orientadores ao votar com $28 \%$ das citações, assim como gostariam de mais atividades de lazer ao citarem com $26 \%$. Quanto à infra-estrutura as citações se mantiveram em $20 \%$. Houve apenas uma citação exigindo "preservar mais".

Melhores serviços viriam atender às necessidades do visitante em conhecer mais sobre o ambiente visitado. A exigência de mais atividades de lazer é reflexo da desinformação sobre o que e como se pode conciliar numa Unidade de Conservação. O visitante demonstrou querer estar mais próximo naquele espaço, transformando-o em algo familiar, seu lugar de lazer e recreação.

As questões analisadas mostraram um visitante que não tem sido motivado a se envolver e compreender suas relações de troca com o ambiente visitado. Ele se inseriu como co-responsável pela conservação ambiental, acredita que a visitação em áreas naturais pode contribuir à preservação ambiental, mas ainda se contradiz quanto aos possíveis impactos negativos. Mostrou-nos a necessidade de se aprimorar ou mesmo implementar melhores serviços de informação e orientação aos visitantes, que querem aprender, mesmo que seus valores ainda estejam subliminados.

O visitante, como perceptor e aprendiz, detém valores pessoais que determinam diferentes necessidades, interpretações e interações.

\section{DA PERCEPÇÃO À INTERAÇÃO}

Objetivando conhecer a percepção do visitante, sobre atributos da paisagem no PEG, registramos comentários individuais, muitas palavras soltas, e procuramos convergir em blocos que expressassem uma compreensão sobre o exercício da atividade turística no ambiente que lhe foi ofertado a observar.

Utilizamos um painel, montado no Centro de Visitantes, com fotos dos lugares pelos quais o visitante obrigatoriamente caminha pelas trilhas e acessos. A cada foto relacionamos perguntas abertas, que o visitante ia respondendo foto por foto. As fotos são imagens ou situações sobre as quais se quer conhecer a percepção dos entrevistados. Tentou-se buscar a essência do processo perceptivo na interação do visitante com o ambiente visitado. No texto expusemos parte das fotos, sem prejuízo às interpretações.

A Figura 5 objetivou analisar a percepção, da paisagem em segundo plano e uma interferência humana em primeiro plano. $O$ acesso construído não foi estranho 
FIGURA 5 - PAISAGEM E ACESSO

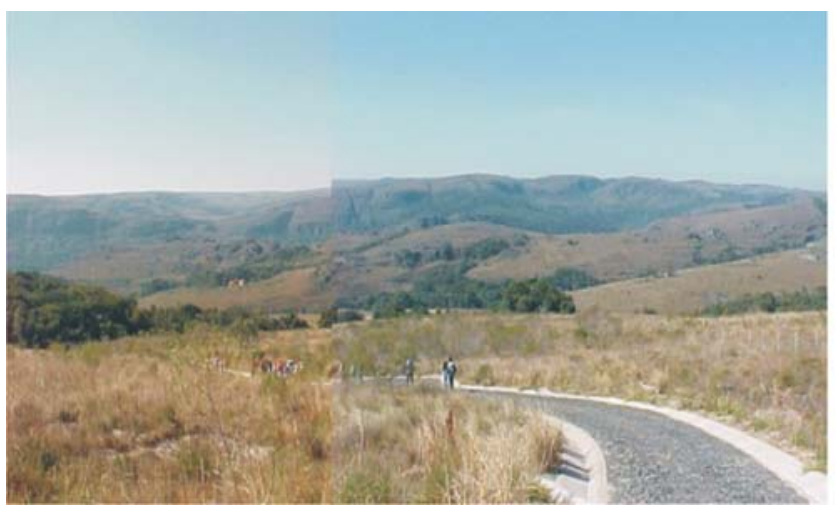

à maioria das pessoas, de origem urbana, familiar àquela imagem. A visão da estrada não agradou a 3 pessoas; 1 entrevistado viu como positivo a "proteção contra erosão", e outro considerou o "acesso bem planejado". O segundo plano foi mais valorizado, as pessoas enaltecendo as sensações vividas e lembradas: "ambiente e ar puro"; "vento no rosto".

A Figura 6 expõe o atrativo principal, Cachoeira Ponte de Pedra. Buscou-se conhecer o impacto da imagem sobre os sentidos, pois além da visão, temos os sons das águas e dos andorinhões, o sentido de profundidade e altura no local de ver a cachoeira, que é aberto e à beira de uma escarpa. Naquele local não há construções, tendo gerado um comentário positivo de que "precisamos aprender a interferir menos". Expressões como "paz e tranqüilidade", "riqueza natural" tiveram $50 \%$ de citações. A percepção do conjunto geográfico foi bem citada como, por exemplo "paisagem com água, rios são mais bonitas que só montanhas", "a vida brotando da natureza" (ao ver a cachoeira e andorinhões saindo das fendas). Em dois comentários encontramos os visitantes integrados ao ambiente, percebendo-o

FIGURA 6 - PAISAGEM - CACHOEIRA PONTE DE PEDRA

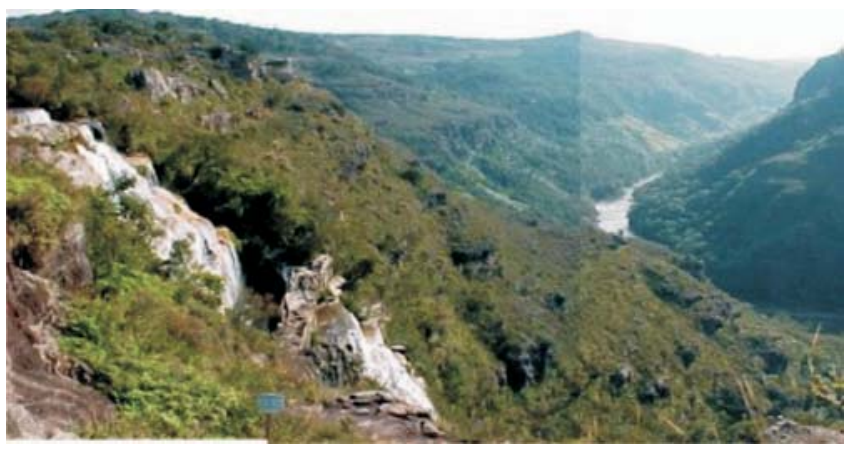

como seu lugar ao "se sentir cercado pela natureza", ou o outro que ao ver a foto lembrou que "ao vivo sente um bem imenso na alma". Realmente, do ponto de observação se pode sentir um envolvimento pelo cenário, introspectivo, apesar de nos posicionarmos mais alto.

A Figura 7 provocou comentários polêmicos, pois era intenção interpretarem as imagens do mesmo local, com e sem pessoas; o ambiente social pela convivência das pessoas, o cultural pelo hábito de se agruparem nas fotos para o registro dos momentos de confraternização. Esclarecemos que naquele local não é permitido às pessoas se posicionarem como estão, em face do grande perigo. É permitido o acesso de onde se vê a paisagem. As cenas foram para um exercício didático em contribuição à dissertação. Após respondido o formulário, explicava este fato ao entrevistado. Três pessoas citaram que as "pessoas interagiam em equilíbrio com o ambiente", denotando um processo perceptivo desprovido de valores ambientais cognitivos, ainda que os sensoriais induzem à beleza cênica. Outro afirmou que "a presença das pessoas dá mais alegria ao ambiente"; pode até ocorrer essa situação, mas não naquele local, de grande fragilidade ambiental pelas formações rochosas areníticas. Contrapondo ao anterior, quatro visitantes afirmaram que "paisagens são mais bonitas sem pessoas". Um entrevistado (designer, 25 anos, Curitiba) evocou a ambigüidade, pois ao mesmo tempo em que temos "a vontade de ver a paisagem sem aquelas pessoas, elas teriam o direito de estarem lá tanto quanto o observador". Esta é uma situação clara que o entrevistado necessitaria de mais informações sobre o ambiente (fragilidade do arenito e riscos).

A Figura 8 compõe-se de duas imagens exibindo o ambiente construído e o natural. Com elas pretendia-se registrar as percepções dos entrevistados, ao caminharem nas passarelas, muito próximos à rede de alta tensão. $A$ imagem do mirante deveria remeter às lembranças do visitante do momento em que vislumbrava a paisagem do canyon. Registramos $91 \%$ das citações com frases favoráveis às estruturas, sendo as mais citadas: "estrututras bem planejadas"; intervenção foi mínima"; facilita a vida dos visitantes"; modificou o ambiente para fornecer infra-estrutura/ mal necessário". Apenas um entrevistado comentou sua percepção sobre a rede de alta tensão citando que "era essencial para o desenvolvimento". Dessas impressões, a penúltima denotou alguma percepção sobre a harmonia do conjunto natural e construído; as demais expuseram uma visão pelo racional. Mais determinista ainda foi o comentário de um visitante dizendo que a "madeira dura pouco, deveriam substituir por concreto". Os seus valo- 


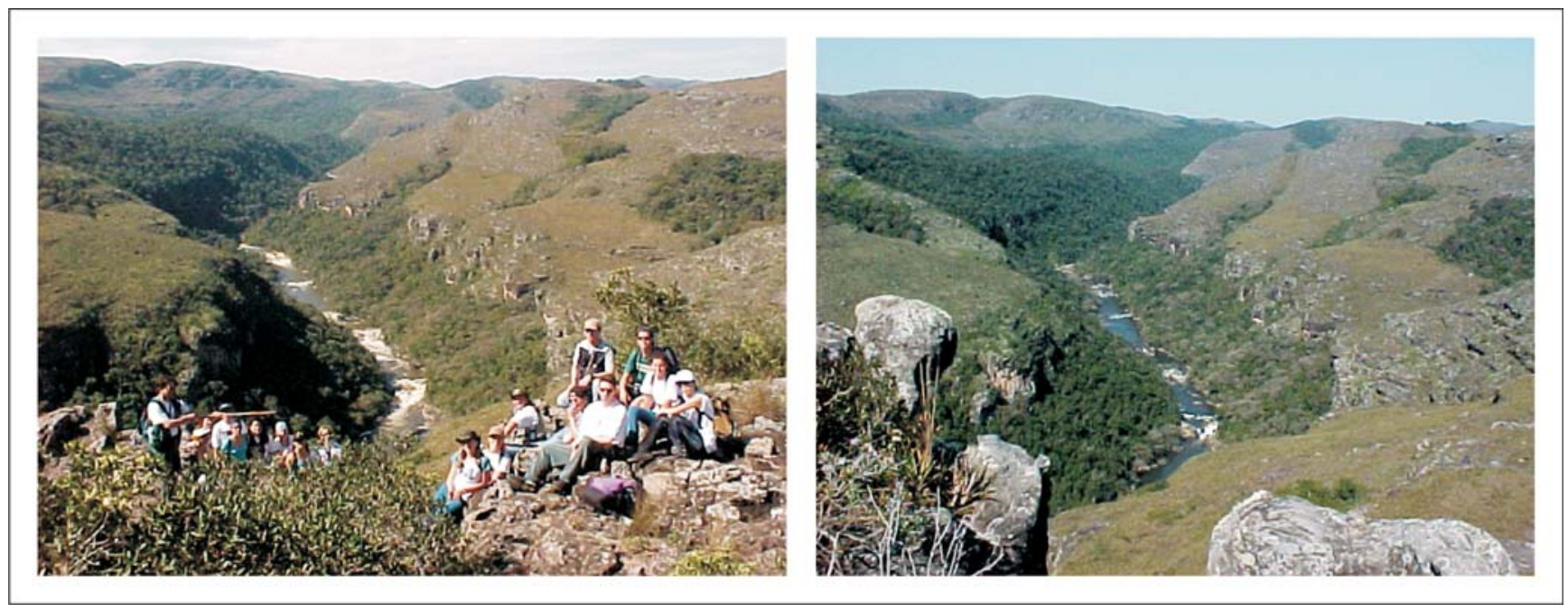

FIGURA 8 - QUAL A PERCEPÇÃO SOBRE O AMBIENTE NATURAL E CONSTRUÍDO

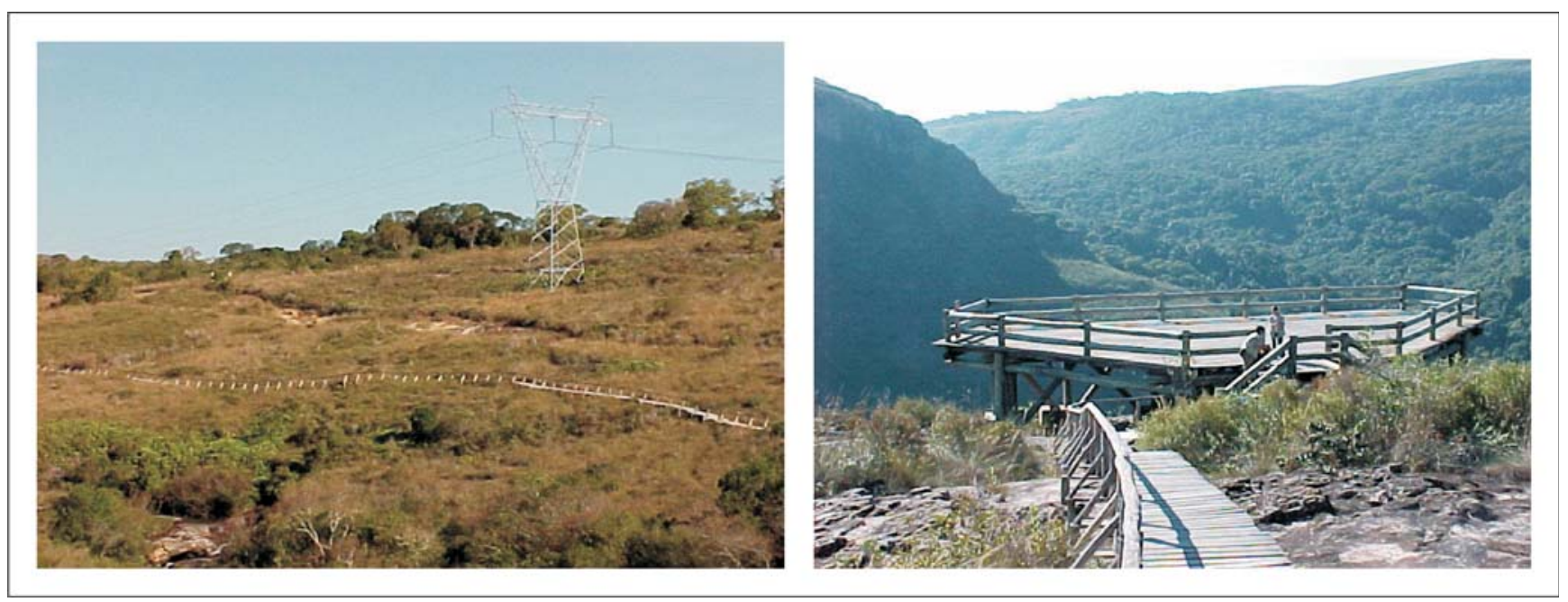

res pragmáticos, racionais, o levaram a essa percepção (engenheiro, 65 anos, T. Borba). Dois visitantes perceberam que a passarela "não condiz com o ambiente" (Comércio Exterior, 36 anos, Curitiba) e que as estruturas eram "agressivas, geravam poluição visual" (advogado, 35 anos, Curitiba). Denota-se que não houve qualquer comentário recordando o momento vivido, experimentadas as sensações ao caminharem pela passarela e apreciado a paisagem percebida do mirante. O racional superou o emocional nessa análise, dando outra forma à interação entre visitante e o ambiente, enfatizada nos mecanismos cognitivos.

\section{DAS PERCEPÇÕES ÀS CONSTATAÇÕES NA BUS- CA DE UMA SITUAÇÃO DESEJADA - CONSIDERA- ÇÕES FINAIS}

$\mathrm{Na}$ busca de responder ao problema postulado, e identificar o quadro momentâneo dos atores e fatores intrínsecos ao tema, estabelecemos como objetivo geral "compreender a percepção dos visitantes sobre as relações entre o Ambiente e as Atividades Turísticas que se desenvolvem no Parque Estadual do Guartelá".

Não se estabelecendo como pressupostos, mas afirmações, que deveriam ser testadas através da aná- 
lise da evidência dos dados empíricos, enunciamos três hipóteses particulares.

- O desconhecimento do visitante sobre a sua conduta nas atividades de lazer no Parque Estadual do Guartelá compromete a sua participação na conservação da integridade daquele ambiente.

- $\quad$ O envolvimento dos visitantes mediante informações sobre o Parque Estadual do Guartelá e questões ambientais poderá levá-lo à tomada de consciência sobre sua conduta na prática das atividades de lazer naquela Unidade de Conservação.

- A integridade do ambiente determinará o grau de satisfação dos visitantes.

Elas exprimem idéias cuja demonstração permitiu alcançar as várias etapas na construção total do raciocínio, levando em conta o quadro atual em contraposição ao teórico, ou ainda, a uma situação desejada.

Nossa base teórico-conceitual e pesquisas a campo, fundamentando a comprovação das hipóteses, nos levaram as principais constatações, que:

- $\quad$ os valores de intelecto não garantiram os conhecimentos sobre questões ambientais e nem creditaram, ao visitante, maior compreensão sobre sua conduta no PEG;

- o ambiente no PEG é percebido sob outros vieses da percepção e conhecimento;

- o visitante gostaria de praticar outras atividades de lazer, nem sempre compatíveis com os objetivos de uma Unidade de Conservação;

- os visitantes não têm uma percepção clara sobre os possíveis impactos negativos que possam ser gerados pela visitação;

- $\quad$ os entrevistados não se sentem co-responsáveis na conservação ambiental;

- o processo de recepção e orientação aos visitantes é falho por falta de clareza nas informações, assim como está deteriorado o sistema de sinalização;

- os procedimentos adotados atualmente no PEG não estão oportunizando, ao visitante, conhecimentos sobre o ambiente e condutas, de forma que possa contribuir ao seu envolvimento e comprometimento com os objetivos daquela UC;

- os atributos do ambiente construído e o social pouco interferiram na avaliação e determinação do grau de satisfação dos visitantes;
- $\quad$ em muitas situações o racional superou o emocional, enfatizando-se os mecanismos cognitivos sobre os perceptivos, ao constatarmos opiniões favoráveis ao conjunto paisagístico formado pelas estruturas, relevo e vegetação.

- $\quad$ os entrevistados não fizeram comentários desabonadores ao ambiente natural;

- ao presenciar os dois principais atrativos, Mirante e Cachoeira Ponte de Pedra, a percepção predominou no processo experiencial, estimulando os sentidos e agregando valores que serão posteriormente lembrados e compreendidos.

Esses tópicos nos levam a concluir, respondendo ao problema, que a atividade turística e o ambiente no PEG, ofertados aos visitantes, são percebidos e compreendidos sob vieses diversos dos valores conceitualmente concebidos a uma área natural, principalmente uma Unidade de Conservação.

São valores individuais dos entrevistados, entre eles os valores do intelecto e conhecimento, que os levaram a uma percepção e conduta, avaliando positivamente a integridade do ambiente e agregando assim valores de satisfação. $\mathrm{Na}$ conduta adotavam posturas descomprometidas e displicentes. Não procede qualquer afirmação que o visitante esteja errado, pois é a sua subjetividade nos processos perceptivos e cognitivos. Podemos, sim, comparar com os objetivos estabelecidos no Plano de Manejo do PEG.

Recordamos que o Plano de Manejo objetiva assegurar a integridade da UC ao se estabelecer normas para visitações, ordenando as atividades de forma a evitar grandes perturbações ambientais. A permissividade do acesso, assim como a forma, intensidade e quais atividades poderão ser exercidas nessas áreas, está condicionada aos aspectos legais do Sistema Nacional das Unidades de Conservação (SNUC).

Releva-se o fato de que o ambiente foi percebido pelos visitantes como um conjunto harmônico das características físico-geográficas e biológicas, ou seja, a paisagem natural, percebida como íntegra, lhes conferiu um alto grau de satisfação. Aquele ambiente favorece ao envolvimento, aos momentos únicos de reflexão e percepção por meio dos sentidos, imaginados, estimulados e lembrados.

Retomando-se Del Rio (1996), observamos que a percepção pode ser agregada em valores para meIhor interação do indivíduo com o ambiente na prática de suas atividades, entre elas as de lazer.

A compreensão nos remonta ao racional e experiencial, podendo ser formada ou desenvolvida re- 
cebendo informações e construindo-se conhecimentos antes e durante os momentos de lazer. Posteriormente àqueles momentos, novos enfoques poderão vir à tona ao se buscar reminiscências através dos sentidos lembrados.

A construção do conhecimento, ou a transmissão de informações, notadamente em UCs, tem sua eficácia e eficiência através de técnicas em educação ambiental. Nos momentos de lazer, ainda que disponham de pouco tempo, as pessoas se mais receptivas podem ser envolvidas e levadas a interagir e adotar condutas compatíveis com o ambiente visitado.

Esses procedimentos e melhorias na comunicação não vêm sendo adotados no PEG, gerando falhas na relação com os visitantes e não agregando valores. Vindo, pois a comprometer dois objetivos primários do PEG, que são "propiciar condições ao lazer na natureza e ecoturismo e promover a interpretação e educação ambiental" (BRASIL, 2000).

\section{REFERÊNCIAS}

BETTANINI, Tonino. Espaço e ciências humanas. Rio de Janeiro: Paz e Terra, 1982, v. 2. (Coleção Geografia e Sociedade)

BOULLÓN, Roberto C. Planificación del Espaço Turístico. México: Trilhas, 1985. p. 244.

BRASIL. Lei n. 9.985, de 18 de julho de 2000. Regulamenta o art. 225, § 1을 incisos I, II, III e VII da Constituição Federal. Institui o Sistema Nacional de Unidades de Conservação da Natureza - SNUC, e dá outras providências. Diário Oficial da República Federativa do Brasil. 2000.

BRUHNS, Heloisa T. O corpo visitando a natureza: possibilidade de um diálogo crítico. In: SERRANO, Célia; BRUHNS, H. T. (Orgs), Viagens à natureza: Turismo, cultura e ambiente. 2. ed. Campinas: Papirus, 1999. p. 125-140.

DEL RIO, Vicente. Cidade da mente, cidade real. In: DEL RIO, Vicente e OLIVEIRA, Lívia (Orgs.). Percepção Ambiental: a experiência brasileira. São Paulo: Studio Nobel, 1996. p. 3-22.

DUMAZEDIER, Joffre. Sociologia empírica do lazer. São Paulo: Perspectiva, 1979. p. 244. (Coleção Debates)

GADE, Christiane. Psicologia do consumidor. São Paulo: Pedagógica e Universitária, 1980. p. 186.

HEIMSTRA, Norman W.; McFARLING, Leslie H. Psicologia Ambiental. Edusp: São Paulo, 1978. p. 218.

MELLO, J. B. Ferreira. Geografia Humanística: a perspectiva da experiência vivida e uma crítica radical ao positivismo.

\section{VISÃO E EXPECTATIVA FUTURA}

Em face das premissas relatadas, traçamos em tópicos algumas expectativas para o PEG, na busca de uma situação exeqüível.

- Visitantes bem informados, envolvidos, participantes e comprometidos.

- Ações de sensibilização e envolvimento sendo exercidas com os visitantes.

- Materiais promocionais e informativos, como folhetarias e cartazes atualizados.

- Material didático e técnicas em educação e interpretação ambiental adotada.

- Guardas-parque, monitores e condutores em maior número e capacitados.

- Sistema de sinalização devidamente atualizado em nova linguagem.

- Ambiente construído, com programa de manutenção periódica estabelecida.

Revista Brasileira de Geografia, 52 (4), p. 91-115, out/dez, 1990.

MOESCH, Marutschka M. A produção do saber turístico. 2. ed. São Paulo: Contexto, 2002. p. 140.

OLIVEIRA, Lívia. Percepção e representação do espaço geográfico. In: DEL RIO, Vicente; OLIVEIRA, Lívia (Orgs.). Percepção ambiental: a experiência brasileira. São Paulo: Studio Nobel, 1996. p. 187-212.

PARANÁ. Decreto Estadual n. 1286, de 03 de setembro de 1999. Diretrizes para o Turismo em Áreas Naturais no Paraná, documento público elaborado por equipe interinstitucional. Curitiba, dez. 2000.

PINHEIRO, Evandro. Percepção sobre o turismo local pela população de Jaguariaíva-PR. Monografia (Especialização em Ecoturismo) - IBPEX, Curitiba, 2000.

Percepção Ambiental e a Atividade Turística no Parque Estadual do Guartelá-Tibagi-PR. 138 p. Dissertação (Mestrado em Geografia) - Setor de Ciências da Terra, Universidade Federal do Paraná, Curitiba, 2004.

SANTOS, Milton. Metamorfose do espaço habitado. 5. ed. São Paulo: Hucitec, 1997, p. 124.

SILVEIRA, M. A. T. Turismo, políticas de ordenamento territorial e desenvolvimento regional: um foco no estado do Paraná no contexto regional. 272f. Tese (Doutorado em Geografia) Faculdade de Filosofia, Letras e Ciências Humanas, Universidade de São Paulo, São Paulo, 2002. 
PINHEIRO, E. da S. Percepção ambiental e a atividade turística...

STCP - Engenharia de Projetos Ltda. Plano de Manejo do P. E. do Guartelá, contratado pela SEMA/ IAP, dez. 2002. 230 p.

TUAN, Yi-Fu. Topofilia: um estudo da percepção, atitudes e valores do meio ambiente. São Paulo: Difel, 1980.

Geografia Humanística In: CHRISTOFOLETTI, Antonio (Org.). Perspectivas da Geografia. São Paulo: Difel, 1982. p. 143-164.

. Espaço e lugar: a perspectiva da experiência. São Paulo: Difel, 1983.
VELHO, Gilberto. Observando o familiar. In: NUNES, E. (Org.). $A$ aventura sociológica: objetividade, paixão, improviso na pesquisa social. Rio de Janeiro: Zattan, 1978.

YASIGI, Eduardo. Vandalismo, paisagem e turismo no Brasil. In: CARLOS, Ana F. A.; CRUZ, Rita de C. A.; YASIGI, Eduardo (Orgs.). Turismo: espaço, paisagem e cultura. Hucitec: São Paulo, 1996. 